Año 9. Núm. 24 (Edición especial Julio- diciembre 2016)

http://revistainvestigacionacademicasinfrontera.com
Revista de Investigación

Académica sin Frontera

ISSN: 2007-8870

Recibido el 18 de abril de 2016.

Dictamen favorable el 27 diciembre de 2016.

\title{
Estudio Retrospectivo de los Derechos Humanos en México
}

\author{
Alba Yareli Vega Gastelum \\ Dalia Sugey Barreras Aldama \\ Brenda Eloísa Yocupicio Solís
}

\section{Resumen.}

Se destacan las modificaciones constitucionales que se han realizado en México en materia de derechos humanos, estas reformas han trastocado de manera muy importante todo nuestro sistema jurídico, ya que no sólo se adoptan conceptos sobre derechos humanos sino también se modifica la precepción y actuar del estado, ya que se obliga a tutelar la protección de los derechos de las personas por ser el centro rector de la nación. Cuyo objetivo del presente trabajo de investigación se plantea el realizar una descripción y análisis de la evolución de la concepción de los derechos humanos en la legislación mexicana y los tratados internacionales que han dado forma a la concepción actual. Usando como metodología la dogmática jurídica y como técnicas son: un estudio de tipo descriptivo y analítico, para la cual se recurre a las técnicas de investigación documental con fuentes doctrinarias: normativas y jurisprudenciales. Como conclusiones: el tema de los derechos humanos se ha hecho de interés general, convirtiéndose en objeto de análisis y debate cotidiano en todos los involucrados en tratamiento, conocimiento, debate y la protección de los mismos.

Palabras Clave: Derechos humanos. Reformas constitucionales. Sistema jurídico. 
Año 9. Núm. 24
(Edición especial Julio- diciembre 2016)

http://revistainvestigacionacademicasinfrontera.com
Revista de Investigación

Académica sin Frontera ISSN: $2007-8870$

\section{Introducción}

Desde hace varias décadas los derechos humanos han ido adentrando como una necesidad de la sociedad y que ha tomado formas jurídicas y culturales a lo cual ha ido permeando en la vida de la misma sociedad, en la década pasada fue naciendo la tendencia por varios países que conforman la comunidad internacional como una fuerte tendencia al respeto de ellos.

Por lo que culmino en nuestro país con la reforma constitucional en materia de derechos humanos en el diario oficial de la federación el 10 de junio del 2011 donde se establecieron los nuevos fundamentos sobre la protección y tutela de los derechos humanos, en su capítulo primero de la Constitución Política de los Estados Unidos Mexicanos al trascender de garantían individuales a Derechos humanos y sus garantías a lo cual no solo es el planteamiento de nuevos conceptos en la constitución si no una recomposición general de la percepción del aparato gubernamental en todos los niveles Federal, Estatal y Municipal, lo cual implico no solo un cambio de conceptos sino una reeducación de una cultura política, social y jurídica.

Las reformas publicadas en materia de derechos humanos nos han dado pauta a revisar la tutela de los derechos humanos frente aún estado que prácticamente ha admitido de forma cautelosa en la protección y defensa de los derechos humanos, que ha venido tutelando en las distintas legislaciones constitucionales que ha tenido a través de su historia. 


\section{http://revistainvestigacionacademicasinfrontera.com}

Como lo afirma Garcia Ramirez \& Morales Sanchez, (2011) la reforma constitucional en derechos humanos no es ni el primer ni el único que ha dado nuestro país con miras a la vigencia efectiva de los mismos.

Hay que destacar que en México desde otras épocas se han manejado la idea de los derechos humanos, por lo que la idea de ello no fue muy sorpresiva en su promulgación.

\section{Planteamiento del tema}

En esta ponencia se abordara primeramente el análisis de algunos conceptos manejados por tratadistas nacionales e internaciones, sobre los derechos humanos y que han dado pies que se construyan tendencias filosóficas y éticas que han permeado en nuestra sociedad actual.

Cambiando la percepción de actuar del estado mexicano ya que se inserta una idea que es la persona el eje central de toda actividad del estado, por lo que se ha gestado la necesidad hacer compatible nuestra constitución con las obligaciones internacionales en derechos humanos, por lo que se reconoce que existen dos fuentes en nuestro derecho mexicano sobre derechos humanos nuestra constitución y los tratados internacionales que el estado mexicano ha sido parte

Por lo que es necesario analizar diversos los instrumentos internacionales de los cuales México han confirmado su compromiso de proteger y defender los derechos humanos del pueblo mexicano, así como el rango constitucional de los tratados en materia de derechos humanos.

Debemos considerar que el principal tratado internacional sobre derechos humanos como lo afirma;Del Toro de la Huerta , (2012) ningún documento de la historia de la 


\section{(Edición especial Julio-diciembre 2016)}

\section{http://revistainvestigacionacademicasinfrontera.com}

Revista de Investigación

Académica sin Frontera

ISSN: 2007-8870

humanidad ha contribuido tanto a la protección y garantía de los derechos fundamentales como la Declaración Universal de Derechos Humanos

Pero también en mexica en otras épocas se ha realizado la defensa y aplicación de los derechos humanos por lo cual es necesario el realizar un análisis histórico para ver el proceso evolutivo que ha tenido a través de los siglos los derechos humanos en las diversas constituciones que van desde el México Independiente hasta nuestros tiempos

\section{Referencias teóricas}

Los derechos humanos siempre han sido un tema de actualidad lo cual en diferentes épocas se ha analizado y ha sido base de comentarios de toda persona, pero al ser un tema tan controversial, cambiante es un tema de discusión donde no existe una uniformidad en su concepto y en cada época o región se le ha llamado de diferentes manera derechos naturales, derechos individuales, derechos del hombre y del ciudadano, derechos fundamentales, derechos subjetivos, entre otros, pero en si cuentan con la misma esencia la cual se pretende analizar.

La Comisión de Derechos Humanos del Distrito Federal(2016) define Los derechos humanos son derechos inherentes a todos los seres humanos, sin distinción alguna de nacionalidad, lugar de residencia, sexo, origen nacional o étnico, color, religión, lengua, o cualquier otra condición. Todos tenemos los mismos derechos humanos, sin discriminación alguna. Estos derechos son interrelacionados, interdependientes e indivisibles.

Los derechos humanos universales están a menudo contemplados en la ley y garantizados por ella, a través de los tratados, el derecho internacional consuetudinario, los principios generales y otras fuentes del derecho internacional. 


\section{http://revistainvestigacionacademicasinfrontera.com}

Revista de Investigación

Académica sin Frontera ISSN: 2007-8870

El derecho internacional de los derechos humanos establece las obligaciones que tienen los gobiernos de tomar medidas en determinadas situaciones, o de abstenerse de actuar de determinada forma en otras, a fin de promover y proteger los derechos humanos y las libertades fundamentales de los individuos o grupos.

El maestro Carpizo, (2011) es de la idea de que la dignidad humana, como ya asenté, singulariza y caracteriza a la persona de los otros seres vivos, debido a su razón, voluntad, libertad, igualdad e historicidad, y considero que desde una perspectiva jurídica, la dignidad humana es la base del ordenamiento político, jurídico y social de una comunidad, y se asegura su vigencia mediante la defensa y protección de los derechos humanos de la más diversa naturaleza, reconocidos en la Constitución y en los instrumentos internacionales que ese Estado ha ratificado. Asimismo, la dignidad humana es el fundamento del derecho internacional de los derechos humanos.

Desde esta óptica, una primera definición de los derechos humanos puede ser: el conjunto de atribuciones reconocidas en los instrumentos internacionales y en las Constituciones para hacer efectiva la idea de la dignidad de todas las personas y, en consecuencia, que puedan conducir una existencia realmente humana desde los ámbitos más diversos, los que se imbrican, como el individual, el social, el político, el económico y el cultural

Ellnstituto de Investigaciones Jurídicas, (1994)se ha pronunciado sobre la concepción de los derechos humanos como; “... el conjunto de facultades, prerrogativas, libertades y pretensiones de carácter civil, político, económico, social y cultural, incluidos los recursos y mecanismos de garantía de todas ellas, que se reconocen al ser humano, considerado en lo individual y colectivamente" 


\section{http://revistainvestigacionacademicasinfrontera.com}

Revista de Investigación

Académica sin Frontera ISSN: 2007-8870

Para el autor Luis Bazdresch, (2000) menciona que es difícil dar una definición precisa de los derechos humanos porque agrupan facultades con distintas características y efectos, así que propone una noción de conjunto, en términos muy generales y prácticos; “... los derechos humanos son facultades que los hombres tienen por razón de su propia naturaleza, de la naturaleza de las cosas y del ambiente en el que viven, para conservar, aprovechar y utilizar libre pero lícitamente sus propias aptitudes, su actividad, y los elementos de que honestamente pueden disponer a fin de lograr su bienestar y su progreso personal, familiar y social".

Para el autor Luis Diaz muller, (1992) los derechos humanos “... son entendidos como aquellos principios inherentes a la dignidad humana que necesita el hombre para alcanzar sus fines como persona y para dar lo mejor de sí a la sociedad, son aquellos reconocimientos mínimos sin los cuales la existencia del individuo o la colectividad carecerían de significado y de fin en sí mismas. Consisten en la satisfacción de las necesidades morales y materiales de la persona humana"

Por su parte, José Castán Tobeñas, (1992) define la acepción derechos del hombre con el siguiente contenido: “...aquellos derechos fundamentales de la persona humana considerada tanto en su aspecto individual como comunitario que corresponden a este por razón de su propia naturaleza y esencia, y que deben ser reconocidos y respetados por todo poder y autoridad y toda norma jurídica positiva, cediendo no obstante en su ejercicio, antes de las exigencias del bien común..."

JackDonnelly, (1998) manifiesta que los derechos humanos “...son literalmente los derechos que una persona posee por el simple hecho de que es un ser humano: droits de l'omme, Menschenrechte, los derechos del hombre". 


\section{http://revistainvestigacionacademicasinfrontera.com}

Roccatti, (1995)expresa que los derechos humanos "son aquellas facultades y prerrogativas inherentes a la persona humana que le corresponden por su propia naturaleza, indispensables para asegurar su pleno desarrollo dentro de una sociedad organizada, mismos que deben ser reconocidos y respetados por el poder público o autoridad debiendo ser garantizados por el orden jurídico positivo"

Lo cual se deduce de los diversos conceptos citados que son prerrogativas inherentes a una persona de formas muy diversas como son civil, política, económica, social, cultural y ambiental, de los cuales son indispensables para cualquier individuo en su desarrollo y desenvolvimiento dentro de toda sociedad.

\section{Los derechos humanos a través de la historia}

El autor Jacobo Marín, (2015) análisis de la organización judicial e instituciones jurídicas aztecas es preponderante en la historia del derecho mexicano, pues resulta interesante para el jurista moderno conocer cómo se impartía justicia en el Estado mexica y sus señoríos, desde los primeros bríos de esta civilización hasta la conquista española. La práctica de las normas consuetudinarias y legales en los tribunales aztecas nos invita a adentrarnos no sólo en el carácter jurídico de una civilización grandiosa, sino también en sus costumbres y reglas sociales, las cuales estaban ligadas íntimamente a la religión; pese a que dichas normas no siempre fueron consignadas por escrito, eran conocidas y respetadas por la comunidad.

A lo que manifiestan diversos estudiosos del teman en esta época ya había un reconocimiento de reglas específicas tanto civiles como penales que regulan a los individuos, así como tribunales orales que se encargaban del buen desarrollo dela comunidad, a lo que se desprende la existencia de ciertos derechos relativos al ser humano. 


\section{http://revistainvestigacionacademicasinfrontera.com}

Revista de Investigación

Académica sin Frontera ISSN: 2007-8870

La Suprema corte de Justicia de la Nacion, (2004) nos manifiesta la Colonia, basados en virtud de principios religiosos y morales producto de la evangelización de los aborígenes, lo que da lugar a una tendencia de protección hacia los habitantes originarios de la Nueva España, como lo revelan los preceptos protectores de los aborígenes, contenidos en las Leyes de Indias.

En la Constitución de Cádiz de 1812, no hay un apartado específico para los derechos humanos, sin embargo hay un reconocimiento de los mismos:

Art. 4. La Nación está obligada a conservar y proteger por leyes sabias y justas la libertad civil, la propiedad y los demás derechos legítimos de todos los individuos que la compone

La Constitución de 1814 contiene, en su capítulo V, intitulado "De la igualdad, seguridad, propiedad y libertad de los Ciudadanos", un amplio catálogo de derechos, precisándose, en el artículo 24 del Texto Constitucional, lo siguiente:

Art. 24. La felicidad del pueblo y de cada uno de los ciudadanos consiste en el goce de la igualdad, seguridad, propiedad y libertad. La íntegra conservación de estos derechos es el objeto de la institución de los gobiernos y el único fin de las asociaciones políticas.

La primera Constitución del México independiente de 1824, no incluye específicamente un apartado de derechos, sin embargo, hace alusión a la libertad

De expresión e imprenta, a la inviolabilidad del domicilio, a la prohibición de detenciones sin orden judicial, a la no confiscación de bienes, a lo no aplicación de leyes retroactivas y al acceso a la justicia.

Tena Ramirez, (2005)nos manifiesta Leyes Supremas de 1836 y 1843, establecen de manera hacen referencia a los derechos humanos de la siguiente manera: 


\section{(Edición especial Julio- diciembre 2016)}

\section{http://revistainvestigacionacademicasinfrontera.com}

Revista de Investigación

Académica sin Frontera

ISSN: 2007-8870

1836: Bases y Leyes Constitucionales de la República Mexicana en su artículo $2^{\circ}$. Establece: "A todos los transeúntes, estantes y habitantes del Territorio mexicano, mientras respeten la religión y las leyes del país, la nación les guardará y hará guardar los derechos que legítimamente les correspondan: el derecho de gentes y el internacional designan cuáles son los extranjeros: una ley constitucional declarará los particulares al ciudadano mexicano"

La Constitución de 1843 establecía en su artículo 9․ Un conjunto de derechos para los habitantes de la República.

El Acta Constitutiva y de Reformas de 1847, instituía que una ley fijará las garantías de libertad, seguridad, propiedad e igualdad de que gozan todos los habitantes de la República, y establecerá los medios de hacerlas efectivas.

En la Constitución Federal de 1857 hacía referencia a que el pueblo mexicano reconoce, que los derechos del hombre son la base y objeto de las instituciones sociales. En consecuencia declara, que todas las leyes y todas las autoridades del país, deben respetar y sostener las garantías que otorga la presente Constitución

La (Suprema corte de Justicia de la Nación, 2004) nos manifiesta la Constitución Mexicana es considerada como una de las primeras que contiene un catálogo de derechos esenciales de los individuos, pero, además, con el objeto de proteger a los sectores de la sociedad que, por su especial situación de desventaja, requieren de mayor protección, como es el caso de los trabajadores, los campesinos y los indígenas, comprende también los derechos sociales, siendo pionera en el mundo en consignar este tipo de derechos.

La Constitución vigente desde 1917 desde su promulgación hacía alusión a los derechos del hombre con el término "garantías individuales", sin embargo con la reforma de 2010 dicho concepto cambia al de "derechos humanos", plasmando un 


\section{(Edición especial Julio-diciembre 2016)}

\section{http://revistainvestigacionacademicasinfrontera.com}

Revista de Investigación

Académica sin Frontera ISSN: 2007-8870

catálogo muy amplio siendo la cuarta parte del articulado constitucional, que se complementa con las disposiciones establecidas en los tratados internacionales del cual nuestro país es parte.

El 6 y 10 de junio de 2011 se publicaron en el Diario Oficial de la Federación, dos reformas constitucionales que transforman radicalmente el modelo de organización jurídica del estado mexicano; a tal grado que podríamos decir que es la reforma constitucional más importante desde 1917, en que fue expedida la constitución mexicana vigente; pues modifica sustancialmente la llamada "parte dogmática" de la constitución.

Esta reforma contiene modificaciones importantes en aspectos sustantivos, orgánicos y procesales, respecto a los derechos humanos.

La reforma publicada el 10 de junio de 2011, implica modificaciones conceptuales y epistemológicas a la noción de los derechos humanos, que impactan sustancialmente en lo que se venía considerando como nuestra propia "Teoría de los Derechos Humanos."

En el artículo 1ํ. Constitucional, se regresa a la visión iusnaturalista que prevalecía en la constitución de 1857, al establecer que la constitución reconoce los derechos humanos, a diferencia del texto original de 1917 que consideraba las garantías individuales como algo otorgado por la propia norma.

Con dichas reformas dejaron de existir las "garantías individuales" (como concepto), para dar paso a de "derechos humanos", igualmente, se está dando a los tratados de derechos humanos el mismo nivel que la propia constitución (se podrá hasta promover amparo por violación a tratados), y se incorpora a la constitución el "principio pro homine" o "principio pro persona" como fundamento básico en la interpretación de normas relativas a derechos humanos. 


\section{(Edición especial Julio-diciembre 2016)}

\section{http://revistainvestigacionacademicasinfrontera.com}

Revista de Investigación

Académica sin Frontera

ISSN: 2007-8870

Asimismo, se incorporan la interdependencia, universalidad indivisibilidad y progresividad, como principios rectores que rigen los derechos humanos.

En la reforma se incorporan los derechos humanos como un principio a seguir en materias como De los Derechos Humanos y sus Garantías Artículo 1; La educación artículo 3ro; El libre tránsito de las personas en el artículo 11; La no autorización de la celebración de tratados para la extradición de reos políticos, ni para la de aquellos delincuentes del orden común que hayan tenido en el país donde cometieron el delito, la condición de esclavos. Artículo 15; La readaptación social de delincuentes artículo 18 y La política exterior mexicana artículo 89 fracción $\mathrm{X}$ entre otros.

\section{Los Derechos Humanos a Nivel Internacional}

Sus antecedentes de la protección de los derechos humanos nacieron sus primeras regulaciones en los siglos XVII, pero tuvo más auge al finalizar la segunda guerra mundial teniendo como cúspide la creación de las naciones unidas, donde los miembros de la comunidad internacional al ver las vejaciones cometidas en contra de la población civil se dieron a la tarea de incorporar a la Carta de las Naciones Unidas el instrumento adecuado para garantizar que los derechos de todas las personas estuvieran protegidos en cualquier lugar y en todo momento. Dicho instrumento sería consolidado como la Declaración Universal de Derechos Humanos (DUDH), en 1946, la que permitiría salvaguardar los derechos humanos y las libertades fundamentales inherentes de todo ser humano, constituyendo así el fundamento de las normas internacionales sobre derechos humanos, independientemente de la nacionalidad, lugar de residencia, género, origen nacional o étnico, color de piel, religión, idioma o cualquier otra condición.

A partir de la celebración de la Declaración Universal de Derechos Humanos como lo manifiesta la Suprema Corte de Justicia de la Nación,(2011) han surgido tratados 


\section{http://revistainvestigacionacademicasinfrontera.com}

internacionales en materia de derechos humanos en los que México ha ratificado, a continuación se hará referencia a los de carácter general:

Nombre

1. Carta de la Organización de los Estados Americanos.

2. Carta de las Naciones Unidas.

3. Convención Americana sobre Derechos Humanos, Pacto de San José de Costa Rica

4. Convención de Viena sobre el Derecho de los Tratados, hecha en Viena el 23 de mayo de 1969.

5. Convención sobre el Estatuto de los Apátridas.

6. Estatuto de la Corte Internacional de Justicia.

7. Pacto Internacional de Derechos Civiles y Políticos.

8. Pacto Internacional de Derechos Económicos, Sociales y Culturales.

20/05/1981

F. DE E.

$22 / 06 / 1981$

$12 / 05 / 1981$

9. Protocolo adicional a la Convención Americana sobre 
Año 9. Núm. 24 (Edición especial Julio- diciembre 2016)

http://revistainvestigacionacademicasinfrontera.com

Derechos Humanos en materia

01/09/1998

de Derechos Económicos,

Sociales y Culturales Protocolo

de San Salvador.

10. Protocolo Facultativo del Pacto

Internacional de Derechos

Civiles y Políticos.

11. Segundo Protocolo Facultativo del Pacto Internacional de Derechos Civiles y Políticos Destinado a Abolir la Pena de Muerte.
Revista de Investigación

Académica sin Frontera ISSN: 2007-8870 
http://revistainvestigacionacademicasinfrontera.com

nacionales, así como los tratados internacionales que forman nuestro ordenamiento jurídico nacional.

Con dichas reformas dejaron de existir las "garantías individuales"; como concepto, para dar paso a de "derechos humanos", igualmente, se está dando a los tratados de derechos humanos el mismo nivel que la propia Ley Fundamental.

Por lo que la Constitución mexicana ha obligado a realizar un cambio integral del estado, ahora el estado es un sujeto a cumplir con la protección de derechos humanos, a lo cual estos cambios ponen en atención y reconocimiento al ser humano, que no solo serán los que están consagrados en nuestra Carta Magna sino también en los tratados Internacionales reconocidos y suscritos por el Estado Mexicano y que han sido ratificados por el Senado de la República, motivando grandes cambios de toda índole dentro del derecho positivo mexicano.

Modificaciones se han estado dando no de la manera ideal pero han ido avanzando conforme se aceptan estos cambios y se realiza un cambio de cultura en la sociedad, sobre un conocimiento pleno de los derechos humanos.

\section{Fuentes consultadas}

BAZDRESCH, L. (2000). Garantias Constitucionales . México: Trillas.

Carpizo, J. (2011). Los derechos humanos: Naturaleza denominación y características . Revista Mexicana de Derecho Constitucional, 12-13.

Castán Tobeñas, J. (1992). Los derechos del hombre. Madrid: Reus.

Comisión de Derechos Humanos del Distrito Federal,. (10 de Octubre de 2016). Comisión de Derechos Humanos del Distrito Federal,. Obtenido de Comisión de Derechos Humanos del Distrito Federal,: http://www.derechoshumanosdf.gob.mx/es/DOCDH/Definicion

Del Toro de la Huerta , M. I. (2012). La Decalració Universal de Derechos Humanos: un texto multidimencional. México: Comisión Nacional de Derechos Humanos. 
Diaz muller, L. (1992). Manual de los derechos humanos. México: CNDH.

Donnelly, J. (1998). Derechos humanos universales, teoria y práctica. México: Gernika.

Garcia Ramirez, S., \& Morales Sanchez, J. (2011). la reforma constitucional sobre derechos humanos (2009-2011). México: Porrúa.

INSTITUTO DE INVESTIGACIONES JURÍDICAS. (1994). Diccionario juridico mexicano. México: Porrúa.

Jacobo Marín, D. (21 de Diciembre de 2015). Tlateomani revista académica de investigación. Obtenido de Tlateomani revista académica de investigación: http://www.eumed.net/rev/tlatemoani/03/djm.htm

Roccatti, M. (1995). Los derechos humanos y la experiencia del obusman en méxico. México: CNDH.

Suprema corte de Justicia de la Nacion. (2004). Las garantias individuales. parte general. En S. c. Nacion, Suprema corte de Justicia de la Nacion (pág. 42.43). México: SCJN.

Suprema Corte de Justicia de la Nación. (31 de Agosto de 2011). sistema bibliotecario scjn.gob.mx. Obtenido de sistema bibliotecario scjn.gob.mx: http://sistemabibliotecario.scjn.gob.mx/sisbib/CST_2012/85660/85660.pdf

Tena Ramirez, F. (2005). Leyes Fundamentales de México 1808-2005. México: Porrúa. 